\title{
Other Ways of Knowing: How School Librarians Can Take a Leadership Role in Addressing Multi-literacies Across the Curriculum in the School Library
}

\author{
Dr. Meghan Harper, Associate Professor \\ Kent State University, School of Library and Information Science \\ Telephone: 1(330) 672-5849 \\ E-mail: sharper1@kent.edu
}

School librarians have a unique, unprecedented, and unparalleled opportunity to affirm their role in students' use of basic literacy skills - reading and writing - while highlighting their relatively new role, guiding students through the acquisition of information through multiple modes of communication with new technologies. School librarians can create and facilitate opportunities for students to enhance their learning and become multiliterate. These learning opportunities and a focus on "core" literacies shed a much needed spotlight on the important role and influence of the school librarian on overall academic achievement and the acquisition of multiliteracy skills that have become a necessity in a changing technological and global environment. This article is based on a presentation given at the International Association of School Librarians Conference in Doha, Qatar (2012), the goals of which were to share an overview of the multiliteracies concept, suggest strategies for facilitating literacy in the school library and classroom, and share professional resources for continued learning and the integration of multiliteracies across the curriculum.

Multiliteracy is a relatively modern term, first coined when ten individuals who had worked professionally in the field of literacy pedagogy, including educators Bill Cope and Mary Kalantzis, met for a week-long discussion and formed the New London Group in 1996. The discussion focused on the future of literacy instruction, asking "what would need to be taught in a rapidly changing near future, and how this should be taught" (Cope and Kalantzis, 2000). The term multiliteracies was used to describe two aspects of literacy instruction in the $21^{\text {st }}$ century: first, the premise that the scope of literacy instruction should extend to include a burgeoning diversity of cultures, and second, that instruction should focus on the increasing availability of a multi-modality of text forms and the connections between these various modes of representation. In short, the New London Group proposed that literacy instruction in the $21^{\text {st }}$ century would need to move beyond traditional reading and writing, and that dialogue between literacy pedagogy professionals would be essential in guiding this expansion.

In their seminal work, A Pedagogy of Multiliteracies: Designing Social Futures (1996), the New London Group traced the impact of new technologies on types of communication, thereby playing a role in changing social environments. The essential evolution in communication can be distilled to the fact that communication is no longer limited to text-based representations of language. Increasingly multimedia, including video, images, and sounds, accompany text as an 
integral component of expression and meaning-making. Technological innovations have altered the very nature of "text" and the manner in which people interact with text; the New London Group argues for the necessity of expanding literacy instruction from traditional reading and writing to include all subsequent forms of text. More information on this concept is available at the following website: New Learning (http://newlearningonline.com/), particularly their Learning By Design page.

Learning by Design is a new literacy pedagogy concept that encompasses the idea that it is a teacher's job to design the appropriate environments wherein students may learn, but ultimately learners are the designers and producers of their own knowledge. Hybrid environments, including online and face-to-face components, will likely become increasingly common. In both online and face-to-face environments, a balanced design will take into account the teaching of "all representations of meaning including linguistic, visual, audio, spatial, gestural and multimodal." Students within these environments must be able to "draw on their own experiences and semiotic literacy practices to represent and communicate meaning" (Cope and Kalantzis, 2012). The latter communication is critical, as a key concept of Design is the idea that individuals are inheritors of patterns and conventions of meaning, but are simultaneously acting as designers of meaning and thus as designers of social futures, potentially workplace futures, public futures and community futures (Cope and Kalantzis, 2000). The difficulty comes in learning not one, right way to communicate (a single literacy), but instead learning how to negotiate differences in meaning as they might vary across cultural, social, and personal contexts (multiliteracies).

Where and how do school libraries situate themselves in the increasingly complex world of literacy education? The answer is actually surprisingly simple: centrally! School libraries have become responsive to changes in how students gather and exchange information, but to truly fulfill their ideal role as the "knowledge center" of the school, as opposed to a staid warehouse of information, school libraries should now look to create and facilitate opportunities for students to further enhance their learning and become multiliterate. Three main strategies will be invaluable: First, librarians should design quality spaces - space that is not limited to physical space but encompasses virtual spaces that are flexible, innovative and inspiring for students. This article includes several examples of library spaces that encompass best practices in facility design for youth. Second, librarians should partner with teachers to design quality work fostering $21^{\text {st }}$ century literacy development. And third, librarians should provide authentic opportunities for students to engage with multiple modes of information and text. The remainder of this article provides an overview of $21^{\text {st }}$ century literacies (information, multicultural, visual, digital and transliteracy), in addition to application ideas for school librarians to encourage student understanding of the literacies and an annotated list of vetted professional resources for the school librarian.

Emphasis on fostering $21^{\text {st }}$ century literacy skills should enable school librarians to situate themselves as leaders, vital to the learning process for students and educators. School librarians' expertise in teaching, information literacy, instructional collaboration and administration of library services and resources, are all essential to creating opportunities for students to engage in the development of multiliteracy skills. While many limitations of old have been surmounted thanks to new technologies and a modern emphasis on literacy development, new challenges 
have arisen, namely meeting students where they are, providing access to multiple modes of information, and promoting transliteracy across mediums. All learning experiences must be geared towards fostering the full spectrum of new literacy skills.

The $21^{\text {st }}$ century requires the cultivation of students who learn, create new ideas, and solve problems not only individually but through collaboration with others in school, at home, and eventually in the workplace (Beers, 2011). In the $21^{\text {st }}$ century, being "literate" means being "able and willing to communicate and understand across differences in language and other modes and media for communication, in ideology, in culture and in geography" (Hill and Nelson, 2009). As school librarians prepare to engage as teachers and instructional partners, thinking about the optimal context for $21^{\text {st }}$ century literacy instruction includes making learning a multi-sensory experience and preparing students for real-world concepts and applications of abstract learning to real life. This becomes a "metaframework" for engagement. Conceptually this term implies that this is an underlying or residual background for learning.

Changes in technology and the workplace will require $21^{\text {st }}$ century students to explore communication and its design and application in an increasingly digital age, acknowledging and embracing the role of social and cultural diversity in the creation of this context. The Beckman Center for Internet and Society at Harvard University defines born digital students as "those who grow up immersed in digital technologies for whom a life fully integrated with digital services is the norm" (Palfrey and Gasser, 2010). However, it is important for all instructors and librarians to remember that digital skills and knowledge are not evenly distributed even amongst these digital natives, having likely been affected by class, race, gender and nationality. In multiliteracies instruction, care should be taken that the inequities in digital skills are addressed so they do not result in a 'participation gap' (Jenkins et. al, 2009). Authentic assessment of student learning plays a critical role in refereeing student participation and learning and thus becomes an inalienable component of all multiliteracies instruction. Authentic assessment in a multiliteracies curriculum should bridge the gaps in curriculum disciplines and encourage full participation in global and cross-cultural exchanges, which also acts to downplay the vaunted value usually placed on teacher knowledge, emphasizing student knowledge design instead.

As school librarians, we see firsthand how students have been influenced by $21^{\text {st }}$ century technology. Two literacies our born digital students should develop as good foundational skills are information and multicultural literacies. According to the American Library Association (ALA), information literacy is: "a set of abilities requiring individuals to recognize when information is needed and have the ability to locate, evaluate, and use effectively the needed information." These skills becomes increasingly important in an environment of rapid technological evolution and information proliferation, which confronts individuals with abundant information sources and modes available from a wide range of information producers with varying degrees of authenticity, validity and reliability (ALA, 2000). Individuals need the ability to synthesize meaning from multiple modes of media, and to judge the quality of their information sources. An abundance of information, without a concurrent growth in information skills, will not result in more educated students.

Practically speaking, "[a]n information literate individual must be able to:

- Determine the extent of information needed 
- Access the needed information effectively and efficiently

- Evaluate information and its sources critically

- Incorporate selected information into one's knowledge base

- Use information effectively to accomplish a specific purpose

- Understand the economic, legal, and social issues surrounding the use of information, and access and use information ethically and legally" (ALA, 2000).

With these component skills, information literacy becomes the backbone for education across all disciplines, in all learning environments, and throughout all levels of education. Not only does it allow for a greater mastery of prescribed content, but more importantly, it provides students with the means to self-direct their extended learning, allowing them to build a personal scaffolding of knowledge. It is, in short, the key to "lifelong learning," preparing students to educate themselves on any topic they may need to master in the future (Gradowski, 2010).

Multicultural literacy and global awareness have become increasingly important as communication and information have been greatly impacted by the advances in technology and the increasingly broad reach of social networking. Multicultural literacy refers to the ability to understand and navigate both one's own culture and others. Culture is an often quoted, but less defined term used to encompass "the unified pattern of human behavior, belief and knowledge that is transmitted from one generation to the next" generally through common practices, values, goals, customs, behavioral norms, and language including idioms and allusions (Oregon Department of Education, 2004). While textual literacy gives students the ability to read words on a page or screen, it is cultural literacy which enables students to understand the words with reference to a particular cultural context. This cultural context is based on a background of "common" knowledge, though what is common knowledge varies widely from one culture to the next. While a base of knowledge common across several cultures, or several bases of knowledge, is useful in becoming multiculturally literate, the most important prerequisite is an ability to navigate carefully through cultures within which one does not possess the full store of common knowledge.

Evolving from multicultural literacy, cultural competence, "the ability to work effectively in cross-cultural situations," could be an invaluable tool for students in their workplace, public and personal futures (Oregon Department of Education, 2004). Regardless of whether individuals intend to cross cultures, it is an inescapable fact that within even one culture there are subcultures and even hidden cultures and anti-cultures, requiring individuals to frequently navigate many cultures coexisting in any one given space. Not only does this require multicultural literacy on behalf of $21^{\text {st }}$ century students, it should be noted the complex nature of even a singular culture requires a certain multicultural literacy competence from all instructors as well. School librarians can foster multicultural literacy by providing opportunities for exploration, and guiding students to high quality resources that offer a window into other cultures.

Important $21^{\text {st }}$ century literacies further include media, visual, and digital literacies. Media literacy in particular has become a key component to $21^{\text {st }}$ century literacy, as media has proliferated to the extent that many of us will spend years of our lives watching TV, listening to music, on the Internet, playing video games, and consuming various other forms of electronic 
media. Media literacy was defined by the Aspen Media Literacy Leadership Institute in 1992 as, "the ability to access, analyze, evaluate and create media in a variety of forms" (Center for Media Literacy, 2011). But the definition has evolved in the two decades since to include an understanding of the role of media in society and an evolution in media literate students from passive consumers to critics and media creators. As well as being able to evaluate media on its own merits, students should learn to place media into a larger context and identify and account for the manipulations inherent in many media messages due to the role of commercialism and advertising in shaping a large swatch of our overall media system. Students should also understand how class, race, gender and other personal factors affect both the media we create and consume (Community Media Center, 2013). "Media literacy skills can help children, youth, and adults:

- Understand how media messages create meaning

- Identify who created a particular media message

- Recognize what the media maker wants us to believe or do

- Name the "tools of persuasion" used

- Recognize bias, spin, misinformation and lies

- Discover the part of the story that's not being told

- Evaluate media messages based on our own experiences, beliefs and values

- Create and distribute our own media messages

- Become advocates for change in our media system” (Media Literacy Project).

Like the other literacies, media literacy has a role to play across the curriculum as examining and discussing media often engenders enthusiasm in students regardless of the content area in question.

Visual literacy is defined as "the reading and writing of visual texts" (Visual Literacy K-8, 2011). The term "visual texts" refers to any type of medium that conveys meaning through images or sequences of images. Examples include street maps, flow charts, menus, websites, even clothing, smiles or gestures! In many situations, images and words are combined to create a visual message that requires interpreting. Visual literacy is an integral skill for $21^{\text {st }}$ century learners particularly, as visual texts are widely used in electronic media, are often complex and multilayered, and can communicate certain information more clearly than verbal texts. Students must learn to interpret not only the chosen images, but also what the choice of images to include and not to include in any given message conveys, as well as how to choose and make use of images in their own messages.

Integrating visual literacy in teaching can be a very valuable tool in the school library. School librarians may foster visual literacy skills by including the use of pictures from students' own lives, other still pictures, hidden images, and film and TV images. Additional learning opportunities may include exploring the connection between sounds and images and crosscurricular activities: the use of charts and diagrams in learning a new math concept, for example, or using images and/or video from a nature documentary during a biology course. The use of visual texts which may be personally relevant to students is likely to engender even greater interest and participation. This might mean asking students to bring in images from their travels during a geography lesson, for example, or asking students to be the creators of visual texts to accompany a written essay on virtually any topic. 
Information, media, and visual literacy may be considered prerequisite skills for students as they encounter digital technologies and begin to develop digital literacy and transliteracy skills. Digital literacy is described as "the ability to effectively and critically navigate, evaluate and create information using a range of digital technologies." It requires one, "to recognize and use that power, to manipulate and transform digital media, to distribute pervasively, and to easily adapt [media] to new forms" (Jenkins, 2009). Most digital formats integrate multiple mediums. Digital literacy is thus interdisciplinary in nature; students are required to utilize information literacy strategies to access, retrieve and interpret information from digital mediums and may need to apply visual, media and multicultural literacies in order to utilize this information. Jenkins also suggests that digital literacy includes, "the ability to use the technology available to accomplish given tasks, demonstrating skills and knowledge," and that youth should be "able to find the information they need, analyze the appropriate materials, and even evaluate which media is the right one for the given task" (2009). School librarians' should provide opportunities for students to compare and contrast informational mediums and formats, dissecting media and bringing all of their information literacy skills to bear on critical analysis of the format and the information included therein. While traditional literacy forms the foundation for all literate interactions, it is increasingly the case that these interactions take place through technological mediums, making digital literacy frequently the means through which all other literacies may be applied.

School librarians can foster digital literacy by providing opportunities to explore multiple digital technologies and guiding students to become savvy information consumers and creators of information and media using digital technologies. Jenkins emphasizes that digital literacy encompasses the skills of creating and manipulating and understanding the inherent power of using digital technologies as a medium to create change, and solve problems. Digital literacy is an essential building block for students to develop transliteracy skills.

Transliteracy is defined as the "ability to read, write and interact across a range of platforms, tools and media from signing and orality through handwriting, print, TV, radio and film, to digital social networks" (TRG, 2006). The availability of digital formats has increased and many students are "plugged in" and have access to a plethora of technologies and formats. However, this does not ensure that all students have equal access or have knowledge to find their way through a plethora of platforms in order to expand their transliteracy skills. School librarians may find the best means to engage and motivate students using digital technologies and foster development of transliteracy skills in a real-world environment is to embrace inquiry-based learning where students can investigate real-world problems and questions and have guided opportunities to engage with multiple technologies.

Ultimately, incorporating multiliteracies across the curriculum helps teachers and students to bridge the gaps that may currently exist in the learning process. Barriers to learning or gaps school librarians address with integration of multiliteracy experiences in the curriculum are described as access to digital content and technology, relevancy of academic work to student life experiences and acquiring skills that will apply in the future. 


$\begin{array}{lll}\text { Digital divide } & \rightarrow & \text { Access } \\ \text { School } & \rightarrow & \text { Home } \\ \text { Real-life } & \rightarrow & \text { Academic content } \\ \text { Current skills } & \rightarrow & \text { Future }\end{array}$

School librarians foster the integration of multiliteracies across the curriculum by providing opportunities for students to utilize resources, both in guided and exploratory environments. Learning is no longer relegated to the school day or confines of the classroom or school library walls. School librarians are increasingly concerned with providing students and teachers with access to both virtual and physical spaces that will resonate and foster learning 24/7. School librarians are concerned with the engagement of learners with multimodal representations of information across multiple platforms.

Librarians have embraced the new demands of the $21^{\text {st }}$ century learner, to create libraries that will inspire creativity and discovery and engage students in multi-sensory learning. Evidence of this focus is seen in all types of libraries world-wide. The 2012 American Libraries Association conference proclaimed, "Transforming our libraries, Transforming ourselves" as the focus of the conference. The annual ALA facility showcase volume highlighted libraries from around the globe recognized for creative, innovative design. The majority of those libraries celebrated for their youth spaces fostered hands-on exploratory learning and the expressive arts, e.g. music, art, dramatic play. Thomas Frey, senior futurist at the DaVinci institute, stated, "The library of the future will be home to highly relevant information experiences, where great ideas happen, and people have the tools and facilities to act on their ideas."

The following libraries showcase design qualities that foster literacy learning:

The Early Learning Center (4,500 sq. ft.) at the Vancouver Community Library in the Fort Vancouver Regional Library District, Vancouver, Washington fosters for its youngest visitors emergent pre-literacy skill development. The space broken down into five zones: Land of Imagination, River Zone, Light Tower, Resource Center, and Mechanical Artworks encompasses 20 interactive structures and hundreds of play elements. Each zone offers multiple opportunities for parents and children to encounter shapes, colors and foster pre-literacy skills with letters. Activities and exhibits change in order for visitors to discover new activities on subsequent visits.

The Fayetteville Public Library of Arkansas was highlighted for both its "green teen space" and inclusive design process. Youth offered design input through focus groups, surveys, and a design chart for a new Otwell Teen Library. A computer lab, gaming area, project room, and communal spaces were added as a result. Sustainable materials, including countertops made from shredded milk jugs and laundry bottles, fabrics and carpet with significant recycled content, zero-VOC paints, a recycled-denim wall, and millwork from certified wood providers are "green" design features. 
School librarians designing new or renovating existing library spaces should base design on the latest information about what is known about how children learn. School library design should rest on a solid foundation of developmentally appropriate practice, universal design for learning and incorporate the latest research in brain development. A premise of developmentally appropriate practice is that learning should be meaningful to the child using instructional practices based on the age and needs of the child. While DAP is a commonly used term in early childhood programs serving children from birth to age eight, this concept is most useful when thinking about creating an optimal environment to provide resources and services that are age and developmentally appropriate. Universal design for learning is based on a set of principles that guide curriculum development to provide all individuals with an equal opportunity to learn. Application in the school library would include the provision of opportunities for individuals to engage with multiple formats of information resources and technologies. Brain-based learning is based on scientific principles about how the brain works. Using these principles, the school librarian can engage learners in an environment that best fosters guided discovery and exploration. These learning experiences will certainly engage students' minds and hearts.

One challenge for school librarians to create and foster multiliteracies is the constant attention to their own professional knowledge and development. Embracing opportunities to share with others in professional venues such as the International Association of School Librarians or their local school library professional organization is a beginning. Pursuing current information via listservs, professional journals and online resources are additional ways school librarians can strive to keep their knowledge current and relevant in an ever-changing technological and global world. The following annotated list suggests professional online multiliteracy resources that the school librarian may want to bookmark for their professional toolbox.

\section{Multiliteracies Online Resources}

- Digital literacy and Media Literacy:

- Common Sense Media http://www.commonsensemedia.org/

- Reviews all types of media, games, movies, apps. Provides discussion questions.

- Provides teacher and instructional materials for digital literacy and vetted media products

- Resources for Pre-K to Adult

- Includes a wealth of reviews on media formats

- Digital Literacy and Citizenship Classroom Curriculum

- Information Literacy resources:

- November learning http://novemberlearning.com/team/

- "The November Learning Team is dedicated to supporting and challenging teachers and students to expand the boundaries of learning. They are committed to helping educators share and explore ideas in a global forum - to motivating children to develop an awareness of their unique selves and exploring how they can contribute positively to the world around them to truly make a difference."

○ Visual Literacy:

- Visual Literacy Toolbox http://www.humanities.umd.edu/vislit/ 
- Secondary to adult

- http://www.iste.org/images/excerpts/MEDLIT-excerpt.pdf

- A pdf excerpt that includes a description of the power of media to create change. The pdf includes visual examples. Geared for middle school and above

- Professional resource for teachers and school librarians on good tips for teaching visual literacy: http://kathyschrock.net/visual/visual.pdf

- Visual literacy K-8 http://k-8visual.info/

- Site for free resources to teach visual literacy

○ Transliteracy:

- Professional resource for school librarians http://www.scoop.it/t/teacherlibrarians-and-transliteracy

- A plethora of articles, resources and information about transliteracy.

- http://pinterest.com/librarianbyday/transliteracy/

- Created by Bobbi Newman

\section{○ Global and Multicultural Literacy:}

- Critical Multicultural Pavilion: Awareness Activities http://www.edchange.org/multicultural/activityarch.html

- http://www11.georgetown.edu/research/gucchd/nccc/documents/checklist.EIE C.doc.pdf

- This checklist is useful to review ideas for implementing ideas for promoting cultural awareness in primary school libraries. 


\section{References}

American Library Association, Association of College and Research Libraries. 2000.

"Information literacy Competency Standards for Higher Education." Guidelines and

Standards. http://www.ala.org/acrl/standards/informationliteracycompetency.

Beers, Sue Z. 2011. Teaching $21^{\text {st }}$ Century Skills: An ASCD Action Tool. Association for

Supervision and Curriculum Development: Alexandria, VA.

Center for Media Literacy. "What is media literacy? A Definition... And More." Literacy in a

Media Age: An Overview and Orientation Guide to Media Literacy Education.

http://www.medialit.org/reading-room/what-media-literacy-definitionand-more.

Community Media Center. "What is media literacy?" http://www.grcmc.org/medialit/what.php.

Cope, Bill and Mary Kalantis, eds. 2000. Multiliteracies: Literacy Learning and the Design of

Social Futures. Routlege: London.

Cope, Bill and Mary Kalantzis. 2001. "Putting Multiliteracy to the Test." Newsletter of the

Australian Literacy Educators' Association. http://www.alea.edu.au/documents/item/59.

Cope, Bill and Mary Kalantzis. 2012. Literacies. University Press: Cambridge.

Gradowski, Gail. 2010. "Why is that so important?" Orradre Library, Santa Clara University.

http://www.scu.edu/docs/SCU/Library/Orradre/services/reference/is/infolit/homepag

e.html\#why.

Healy, Annah. 2008. Multiliteracies and diversity in education: new pedagogies for expanding landscapes. Oxford University Press, USA.

Hull, Glynda and Mark Nelson. 2009. "Literacy, Media and Morality: Making the Case for an

Aesthetic Turn." In The Future of Literacy Studies edited by Mike Bynham and

Mastin Prinsloo, 199-228. The Palgrave Advances in Language and Linguistics series, Palgrave MacMillan: USA.

Jenkins, Henry et. al. 2009. Confronting the Challenges of Participatory Culture: Media

Education for the $21^{\text {st }}$ Century. MacArthur: Cambridge, MA.

Media Literacy Project. "Introduction to Media Literacy."

http://medialiteracyproject.org/sites/default/files/resources/Intro to Media Literacy.pdf.

New Learning. 2012. "Learning by Design Project.” http://newlearningonline.com/.

The New London Group. 1996. "A Pedagogy of Multiliteracies: Designing Social Futures."

Harvard Educational Review 66, no. 1.

http://wwwstatic.kern.org/filer/blogWrite44ManilaWebsite/paul/articles/A Pedagogy of Multiliteracies Designing Social Futures.htm.

Oregon Department of Education. 2004. "Working Definition of Cultural Competency."

Resources on Cultural Competency.

http://www.ala.org/acrl/standards/informationliteracycompetency.

Palfrey, John and Gasser, Urs. 2010. Born Digital: Understanding the First Generation of

Digital Natives. Basic Books: New York.

TRG (Transliteracy Research Group). 2006. Transliteracy.com.

http://nlabnetworks.typepad.com/transliteracy/.

Visual literacy K-8. 2011. "What is visual literacy?" http://k-8visual.info/. 